\title{
Dialogando com narrativas digitais e aprendizagens nos terreiros de candomblé
}

\author{
Máira Conceição Alves Pereira* \\ Stela Guedes Caputo**
}

\section{Resumo}

Este ensaio tem o objetivo de propor um diálogo entre narrativas digitais e aprendizagens em terreiros de Candomblé por meio da apresentação e discussão de dois casos. O eixo da análise recai sobre as diversas redes educativas que se entrelaçam cotidianamente nos terreiros de Candomblé, ultrapassando os seus limites físicos e alcançando o ciberespaço, entendido como um espaço desterritorializante, sem controle centralizado e que existe em potência em um hipertexto mundial interativo, por meio de diversas narrativas digitais. Redes educativas nos formam com processos pedagógicos específicos e nelas nos modificamos, contribuindo para as mudanças que se processam em fluxo e cotidianamente. Os cotidianos representam um local de produção e recriação de conhecimentos e significações. As aprendizagens nos terreiros acontecem tradicionalmente de forma oral. Com o advento da internet e das novas tecnologias da informação e da comunicação, esses saberes podem se espalhar indefinidamente, constituindo novas redes educativas. Como essas narrativas digitais alteram e recriam os cotidianos nos terreiros? De que formas os adeptos do Candomblé atuam sobre essas narrativas, produzindo-as, discutindo-as e modificando-as? Essas são algumas questões que foram discutidas neste ensaio. Para tanto, foram mapeados rastros dessas narrativas digitais em ambos os casos apresentados com o dispositivo da observação participante de candomblecistas em páginas específicas no Facebook, bem como por meio de entrevistas online e presenciais. Os principais parceiros intelectuais são autores que pesquisam a cibercultura, as redes educativas e os cotidianos nos terreiros.

Palavras-chave: Candomblé; narrativas digitais; redes educativas.

* Doutoranda do Programa de Pós-Graduação em Educação - ProPEd/UERJ desde março de 2014. E-mail: mairapereira@uol.com.br

* Doutora em Educação. Professora da Faculdade de Educação e do Programa de Pós-Graduação da UERJ. E-mail: stelauerj@gmail.com 


\section{Dialogando con narrativas digitales y aprendizajes en los terreros de candomblé}

\section{Resumen}

Este trabajo tiene como objetivo proponer un diálogo entre narrativas digitales y aprendizajes en terreros de Candomblé por medio de la presentación y discusión de dos casos. El eje del análisis está en las diferentes redes educativas que se entrecruzan a diario en los terreros de Candomblé, yendo más allá de sus límites físicos y alcanzando el ciberespacio, entendido como un espacio desterritorializante, sin control centralizado y que hay en potencia en un hipertexto global interactivo, por medio de diversas narrativas digitales. Redes educativas nos forman con procesos pedagógicos específicos y en ellas nos cambiamos, en contribución a los cambios que se producen en flujo y cotidianamente. Lo cotidiano representa un lugar de producción y re-creación de conocimientos y significaciones. Los aprendizajes en los terreros tradicionalmente se producen por vía oral. Con la llegada de Internet y de las nuevas tecnologías de la información y la comunicación, estes saberes pueden extenderse indefinidamente, proporcionando nuevas redes educativas. ¿Cómo estas narrativas digitales cambiam y volven a crear lo cotidiano en los terreros? ¿De qué manera los seguidores del Candomblé actuan en estas narrativas, produciéndolas, discutiéndolas y cambiándolas? Estos son algunos de los temas que se discutieron en este ensayo. Para eso, pistas de esas narrativas digitales se mapearon en los dos casos que se presentan con el dispositivo de la observación participante de candoblecistas en las páginas específicas en Facebook, así como por medio entrevistas en línea y presenciales. Los principales socios intelectuales son los autores que investigan la cibercultura, las redes educativas y lo cotidiano en los terreros.

Palabras clave: candomblé; narrativas digitales; redes educativas.

\section{A dialogue with digital narratives and the learning process in a candomnblé center}

\section{Abstract}

This essay intends to analyse digital narratives and the learning processes in Candomble communities by presenting and discussing two study cases. The focus of the analysis is the multiple educational networks that are connected on a day-to-day basis in Candomble communities, and that go beyond its geographical limits, reaching the cyberspace, which can be understood as a space of deterritorialization, with no centralized control and that inhabits a global interactive hypertext trough digital narratives. Educational networks deal with specific pedagogical processes and transform us, contributing to continuous changes. It is possible to create knowledge and meanings on a regular basis. Traditionally, learning happens in the oral form in Candomble communities. With the internet and new communication and information technologies, however, knowledge can be spread and shared freely, originating new educational networks. How do digital narratives, particularly social media, impact and change Candomble communities? How do the Candomblé practicioners produce, discuss and react to those narratives? These are some questions that were presented and discussed in this paper in two study cases, with the focus on digital narratives that were found on Facebook pages. The authors of those digital narratives were interviewed. The bibliography is composed by authors who research cyberculture, educational networks and learning processes in Candomble communities.

Keywords: Candomble; digital narratives; educational networks. 
Sobre o contexto e as questões do ensaio: o desafio e a complexidade da pesquisa

Com Caputo (2012b), se entende os terreiros de Candomblé como espaço de circulação de saberes, de aprendizagens e de conhecimentos. Como assinala a autora, para Freire (1978), "só existe saber na invenção, na reinvenção, na busca permanente que se faz no mundo, com o mundo e com os outros" (CAPUTO, 2012b, p. 350). Este mundo que é o terreiro é atravessado por diversas redes educativas que ultrapassam os seus limites físicos e atingem o ciberespaço, entendido como um espaço desterritorializante, sem controle centralizado e que existe em potência em um hipertexto mundial interativo, por meio de diversas narrativas digitais. Lemos (2010) concebe o ciberespaço como uma entidade real, "parte vital da cibercultura planetária que está crescendo sob nossos olhos" e que colabora para a criação de uma "realidade aumentada", uma vez que ele amplia a realidade e com ela se conecta, sendo considerado também como um "complexificador do real" (LEMOS, 2010, p. 128).

Redes educativas nos formam com processos pedagógicos específicos e nelas nos modificamos, contribuindo para as mudanças que se processam em fluxo e cotidianamente. A noção de cotidianos, em que tudo aprende e tudo ensina, é para Alves (2008) um local de produção e recriação de conhecimentos e significações.

As aprendizagens nos terreiros acontecem tradicionalmente de forma oral. Os candomblecistas contam suas lendas, ritos, ensinam sobre os usos dos artefatos culturais e uns passam esses saberes para os outros oralmente. Com o advento da internet e das novas tecnologias da informação e da comunicação (TICs), esses saberes podem também se espalhar indefinidamente, constituindo novas redes educativas relacionadas aos terreiros.

O eixo da análise deste ensaio se situou nas diversas redes educativas que se entrelaçam cotidianamente nos terreiros, alcançando o ciberespaço, em que seus praticantes aprendem sobre a religião, seus rituais, seus valores e filosofia de vida, sobre as formas de se relacionar entre si, com a Natureza e com os deuses cultuados.
A emergência do campo e do objeto da pesquisa, aqui apresentada de forma preliminar, uma vez que se encontra em desenvolvimento, originou-se em Caputo (2012a), cuja pesquisa de vinte anos com crianças de Candomblé revela que elas escondem sua fé na escola por se sentirem discriminadas, tanto religiosa quanto racialmente, embora tenham crescido aprendendo a amar os Orixás e a cultura de seus ancestrais.

Caputo (2012a) concluiu que fazer parte da religião não se mostra suficiente para assumi-la em outros espaços, sobretudo na escola. O amor ao Candomblé permanece, mas as crianças desenvolvem táticas para lidar com o preconceito e a hostilidade nas escolas, negando e escondendo, muitas vezes, a própria fé.

O papel das narrativas digitais foi analisado, preponderantemente, em sua potência criadora de novos significados para os praticantes do Candomblé, conferindo mais visibilidade para a religião e contribuindo, muitas vezes, para a superação do preconceito, validando práticas e crenças, viabilizando interações e novas aprendizagens e fortalecendo identidades de forma alinhada com a concepção de que as redes se inserem em todas as fibras do cotidiano.

O brincar, o dançar, o cantar, o estar com amigos, o aprender e o ensinar e tantas outras ações compõem e caracterizam o terreiro de Candomblé como uma rede educativa para as crianças e para os demais praticantes da religião. Como nos ensina Alves (2008), há muitos outros espaçostempos de aprendizagens além da escola, em que se vive, se aprende e se ensina. Destacam-se neste artigo os próprios terreiros e as redes sociais na Internet.

Há outra consideração, entretanto, em relação ao papel assumido pelas narrativas digitais para o Candomblé. Por ser uma religião permeada e caracterizada por Àwo, que significa segredos na língua Yorubá, os sentidos atribuídos às variadas narrativas digitais pelos próprios adeptos são múltiplos, heterogêneos e, em alguns casos, podem representar ameaças. Nos terreiros de Candomblé convivem diferentes gerações e suas avaliações e sentimentos sobre imagens compartilhadas em redes sociais relativos à fé que professam são igualmente variados. As narra- 
tivas digitais poderiam, ainda, expor seus praticantes a discriminações e perseguições, resultado da incompreensão de seus fundamentos por pessoas leigas e da intolerância às religiões de matriz africana. Portanto, o papel dessas narrativas digitais pode favorecer a divulgação do Candomblé e o fortalecimento da identidade de seus praticantes e também a emergência de alguns pontos de tensão por meio dos variados usos, por variados autores, dessas narrativas. Em ambos os casos, a oportunidade de debate gerada e de produção de sentido, com disputas de significados, constitui o tecido de uma complexa rede de subjetividades (SANTOS, 1995), em um fluxo de novas aprendizagens e múltiplas possibilidades não excludentes, pois se considera que $o$

\begin{abstract}
ponto crucial é que o ciberespaço é ao mesmo tempo, coletivo e interativo, uma relação indissociável entre o social e a técnica. Essa perspectiva nos leva a pensar o ciberespaço, então, como um potencializador de infinitas ações interativas, um novo espaço de comunicação, de sociabilidade, de reconfiguração e de autorias (SANTOS; SANTOS, 2012, p. 4).
\end{abstract}

Como as narrativas digitais alteram e recriam os cotidianos nos terreiros? De que formas os adeptos do Candomblé atuam sobre essas narrativas, produzindo-as, discutindo-as e modificando-as? Essas foram algumas questões apresentadas neste ensaio e que pretendemos responder parcialmente aqui por meio de dois casos analisados e continuar perguntando ao longo da pesquisa.

\section{Narrativas digitais e aprendizagens nos terrei- ros de Candomblé: diálogos possíveis na análi- se de dois casos}

As narrativas digitais produzidas por candomblecistas e compartilhadas em redes sociais digitais constituem um acervo dinâmico, que se amplia a cada clique, a cada comentário, a cada compartilhamento.

Em conversas com as produtoras destas imagens foi possível tecer algumas redes de significados:
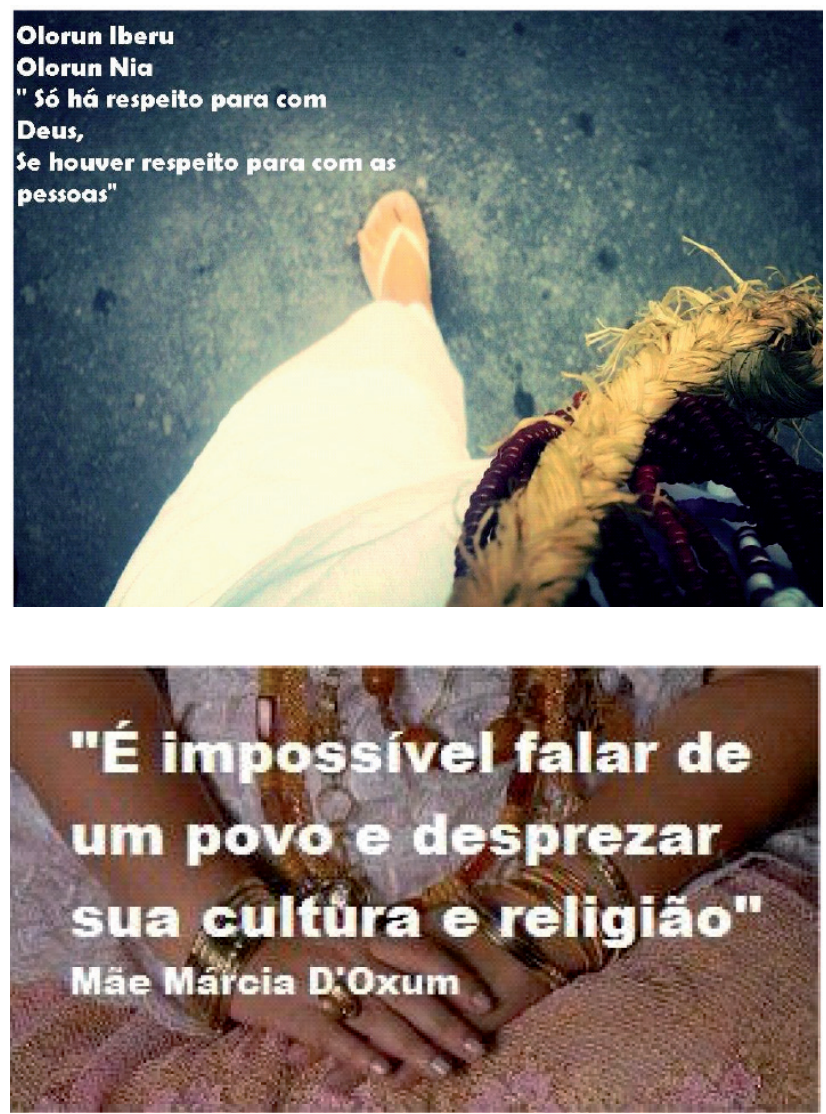

Na primeira imagem, temos o autorretrato de uma recém-iniciada no Candomblé que vivenciou em seu curso de Pedagogia a discriminação religiosa em seu período de preceito, que é a fase que se segue à iniciação na religião. Uma professora Ihe dirigiu ofensas durante as aulas e declarou que sua escolha pessoal e religiosa havia sido equivocada. A autora-personagem da foto publicou a imagem dos seus passos em sua caminhada espiritual e de vida na página no Facebook do Projeto Matrizes Que Fazem, com o qual está diretamente vinculada, associando a imagem a um provérbio africano ensinado por sua İyálorixá (Mãe de Santo), Mãe Márcia D'Oxum, que sintetiza o valor de se respeitar as pessoas como princípio estruturante da religião.

Na segunda imagem, temos citação e fotografia de Mãe Márcia D'Oxum, idealizadora e coordenadora do Matrizes Que Fazem, projeto de ações sociais e afirmativas, sediado e vinculado ao Egbe lle lya Omidaye Ase Obalayo, 
terreiro de Candomblé situado no município de São Gonçalo, no Rio de Janeiro.

A graduanda de Pedagogia da primeira imagem incorpora em seu currículo e em seu percurso formativo ensinamentos de sua İyálorixá e se mostra, de forma cada vez mais implicada, envolvida nas ações educativas e projetos sociais promovidos por seu terreiro. Mãe Márcia tem idealizado e realizado, junto com a equipe do Matrizes que Fazem, projetos de capacitação de pessoas ligadas às comunidades tradicionais de terreiros e tem consolidado seu papel na disseminação do conhecimento e da cultura afro-brasileira. Ela tem contribuído para a formação cidadã e empreendedora dessas pessoas, reunindo em seus cursos candomblecistas das mais variadas $\mathrm{Na}-$ ções, além de outros públicos, como crianças e jovens de sua comunidade. Ela é referência para seus filhos de santo, outras lideranças religiosas e preocupa-se em mobilizar competências para o fortalecimento dos povos tradicionais de terreiros e para a constituição de novos projetos educativos e culturais.

A compreensão das imagens amplia-se ao se observar desdobramentos de sua publicação no Facebook e ao se conversar com os candomblecistas nos terreiros e em outros espaçostempos.

\section{O espaço acadêmico é ocupado pelas can- domblecistas empreendedoras: os saberes afrodescendentes circulando em diferentes espaçostempos}

Acompanhando-se os rastros digitais das duas candomblecistas das imagens apresentadas nesta seção e também por meio de interações com elas, em conversas e entrevistas online e presenciais, foi possível mapear seus interesses ao longo de seus percursos, bem como suas implicações no contexto da própria religião, em seus posicionamentos sociopolíticos e seus impactos dentro e fora dos terreiros, em que ambas continuam atuando lado a lado, em um fluxo de aprender e ensinar.

Com Bruno (2013), podemos compreender o significado desses rastros, cuja complexidade se constitui como um dos principais desafios metodológicos. O rastreamento e arquivamento das ações cotidianas na Internet são possíveis em função da estrutura dessa rede e seus navegadores, em que "toda ação deixa um rastro potencialmente recuperável, constituindo um vasto, dinâmico e polifônico arquivo de nossas ações, escolhas, interesses, hábitos, opiniões etc" (BRUNO, 2013, p. 123). Os rastros possuem uma topologia complexa e variados níveis de visibilidade.

Este ensaio deteve-se em um estrato mais superficial e explícito dos rastros dos candomblecistas selecionados para análise, uma vez que a pesquisa que originou o texto se encontra em estágio inicial. Tratam-se, portanto, de publicações divulgadas e compartilhadas voluntariamente nas redes soc iais.

Da mesma forma que ocupam esses espaços em seus terreiros e em sua comunidade no sentido mais amplo, Mãe Márcia D'Oxum e Adelaine Neves, a dona dos pés fotografados e publicados no Facebook em seu período de preceito, seguem em seus percursos de resistência por meio da difusão de saberes e práticas de matriz africana, fundamentais para a formação do Brasil. Por terem sido convidadas para mediar atividades na UERJ (Universidade do Estado do Rio de Janeiro), a publicação e o compartilhamento das imagens de ambas na divulgação do evento na Universidade, conquistaram outros espaços e viabilizaram o encontro de diferentes pessoas ligadas à produção de conhecimento nos cotidianos das lutas por uma educação inclusiva e antirracista.

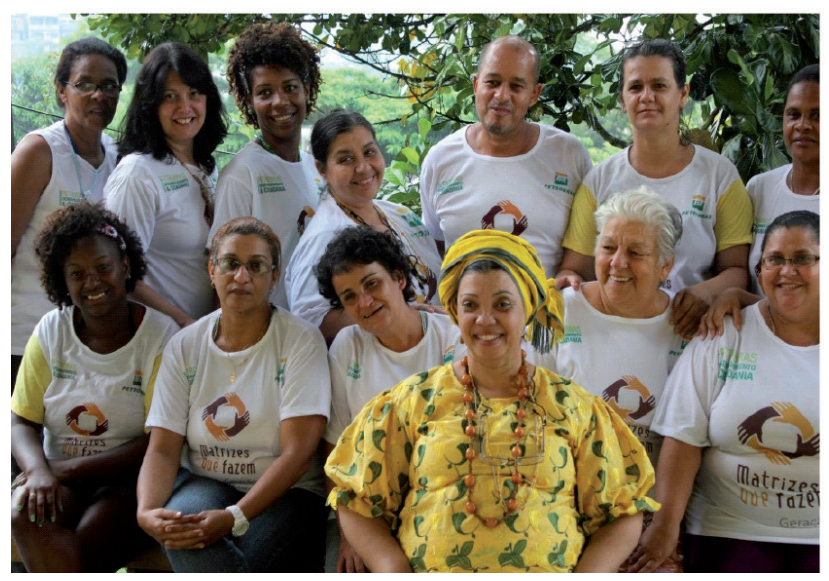

Mãe Márcia, na imagem com equipe e participantes das oficinas do Projeto Matrizes Que Fazem, levou para o 
evento na Universidade um minicurso sobre literatura infantil afro-brasileira, contando como as crianças aprendem em seu terreiro por meio de histórias e valores típi$\cos$ da cultura afrodescendente. Adelaine ofereceu uma oficina de tranças-afro para os participantes do seminário na Faculdade de Educação, menos de dois anos após ter feito a foto de seus passos, quando vivenciou discriminação religiosa em seu curso de graduação, também dentro de uma Faculdade de Educação.
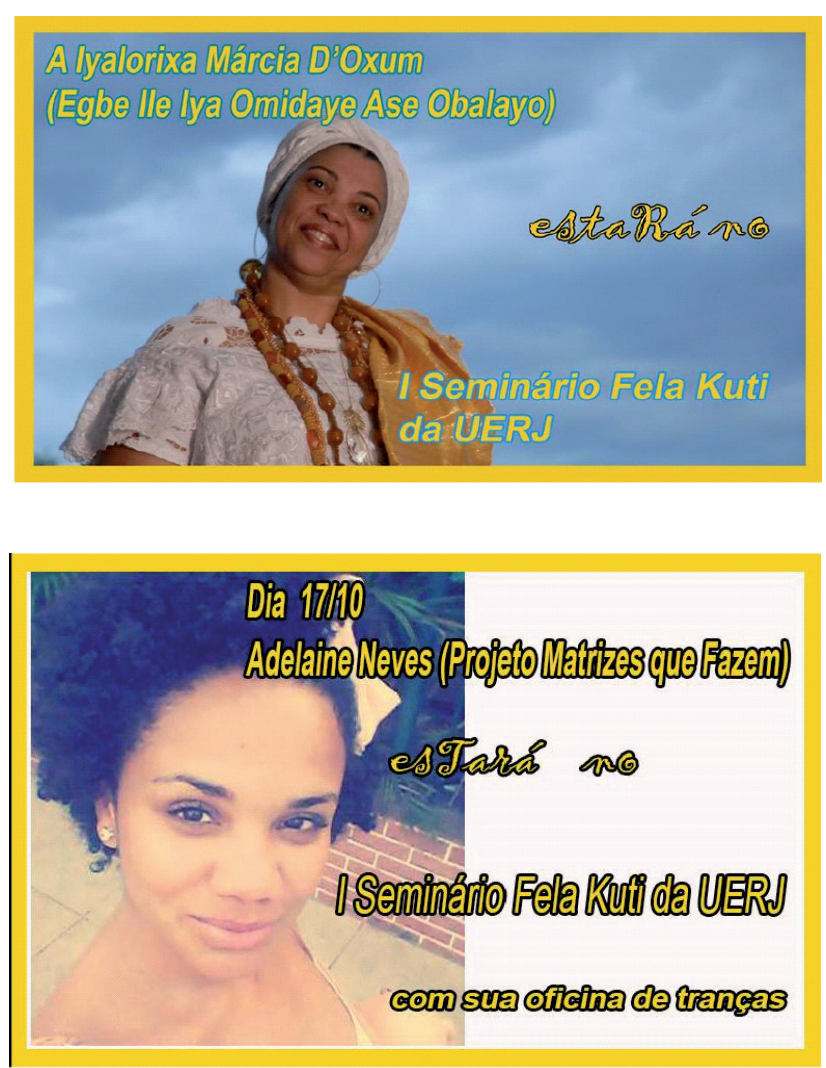

Acompanhando o percurso das duas, mãe e filha segundo o parentesco espiritual e iniciático que as une na tradição do Candomblé, conseguimos verificar o quanto o fortalecimento da identidade negra afro-brasileira e candomblecista se faz presente em suas práticas cotidianas, o quanto aprendem e se modificam mutuamente. $O$ impacto em seu terreiro é significativo. Na oportunidade do encerramento de uma das turmas de um curso de capacitação do Matrizes que Fazem em agosto de 2014, dentro do próprio terreiro e em um projeto específico denominado "Matrizes do Futuro", Mãe Márcia e Adelaine, à frente da coordenação geral do curso, divulgaram também o seminário do qual fariam parte na UERJ, mos- trando a relevância de ocupar espaços e convocando as pessoas à participação. Em alguns momentos da cerimônia de encerramento do curso, tanto Mãe Márcia quanto Adelaine repetiam a expressão "somos de resistência", referindo-se à identidade afrodescendente que as inspira a lidar com muitas adversidades para a realização de seus sonhos e ações empreendedoras.

\section{Educação nos terreiros: a página no Facebook que foi ocupada por imagens de crianças de Candomblé, causando uma alegre desordem}

O livro que inspirou a pesquisa apresentada em seus resultados preliminares neste ensaio, possui uma página no Facebook criada por sua autora em junho de 2012 para divulgar os lugares e datas de lançamento pelo Brasil, além das fotos que ela mesma produzia em sua pesquisa sobre crianças de terreiros e discriminação.

Em julho de 2014, um interessante processo se iniciou com a publicação pela autora de uma foto que não havia sido feita por ela e trazia um grupo de crianças sorridentes que faziam parte de outro terreiro, diferente daquele em que se realiza a sua pesquisa. Estas eram crianças do llê Axé de Ogum Ja:

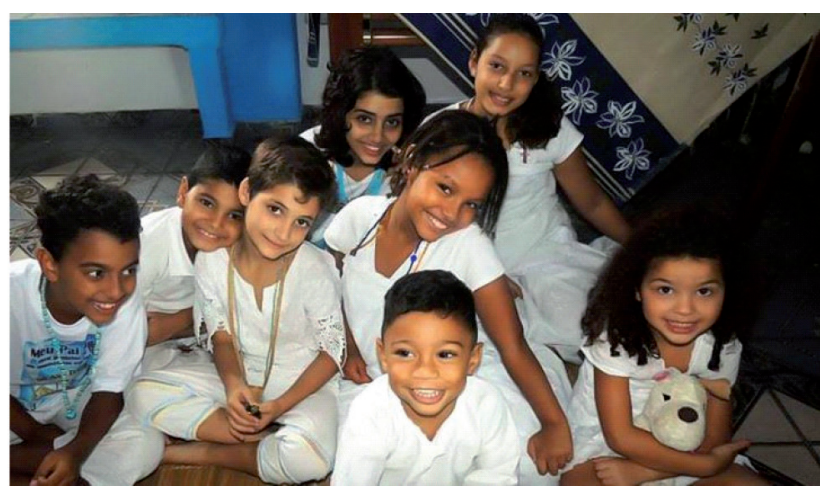

A foto enviada por uma amiga virou capa da página do livro "Educação nos Terreiros" no Facebook em 13/7/2014, deflagrando, além de muitas curtidas, uma série de envios de fotos de crianças dos terreiros das mais variadas nações por seus familiares. A seguir, mais alguns exemplos de fotos enviadas e publicadas na página do livro. Na primeira imagem, o menino João, do llê Axé Oxum Deym, de Recife, tocando no llê Axé Oxóssi Guangoubira, em foto enviada no mesmo dia, 13 de julho. Na segunda, 
Lucy de Oxalá, do llè Asé Elesu, de Porto Velho, Rondônia, em foto enviada pelo pai em 16 de julho:

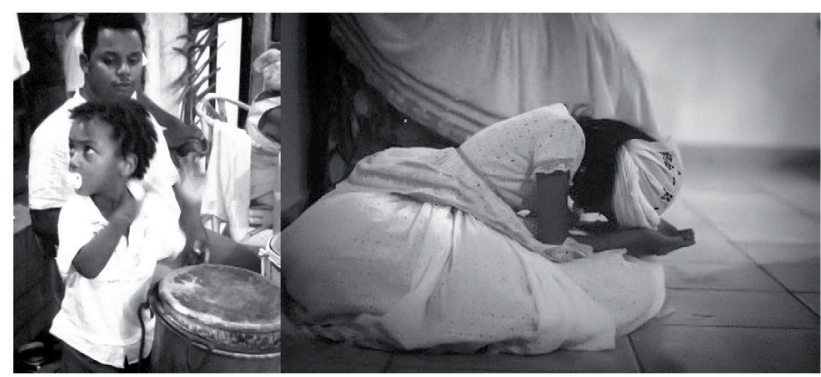

A autora do livro teve sua página no Facebook desorganizada pelas imagens que não eram de sua autoria. A sensação de desordem, revelada em uma das conversas durante a pesquisa, deu, logo em seguida, lugar ao sentimento de alegria pelas imagens que as pessoas fazem em seus próprios terreiros e pelo alcance da sua pesquisa, com espaços para coautorias e para a autoria de tantas outras pessoas, todas ligadas à discussão sobre as aprendizagens nos terreiros. A página atingiu oito mil curtidas no final de agosto.

É também na companhia de Bruno (2013) que refletimos que as tecnologias de ver e ser visto ampliaram-se ainda mais na Internet. Isso torna os indivíduos, simultaneamente, mais sujeitos à vigilância e "relativamente mais autônomos na produção de sua própria visibilidade" (2013, pp. 58-9). A exposição de si não está mais sujeita à autorização e intervenção de terceiros. No caso da página do livro "Educação nos Terreiros", essa ampliação se uniu ao orgulho e à alegria de ver e ser visto, produzindo novos conhecimentos e significações sobre as crianças de terreiros.

\section{A importância de aprender a ser água e ouvir - Àlàáfíà para seguir na pesquisa}

É desafiador tentar mapear alcances e impactos das redes educativas atravessadas por narrativas digitais e como candomblecistas criam seus mundos com elas, colaborando entre si e podendo potencializar lutas contra a intolerância e a discriminação religiosa e racial. É um modo de recriar o laço com a própria religiosidade por meio de novas formas de aprender e de ensinar.
Os casos com os quais dialogamos aqui confirmam a relevância da pesquisa e renovam o entusiasmo com a sua continuidade ao mesmo tempo em que evidenciam sua complexidade e desafio metodológico crescente. Aprofundamento teórico e imersão ainda maior no campo pesquisado são requeridos, bem como a necessidade de recortes dada a vastidão do tema e das narrativas dispersas na Internet.

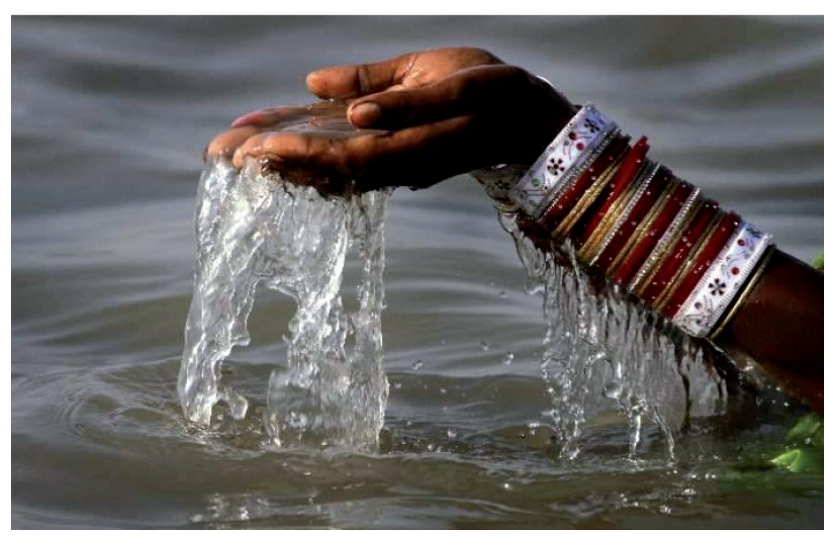

Vem de Mãe Márcia o ensinamento doado durante uma de nossas conversas. Ao ouvir a expressão "faça como a água e contorne os obstáculos", ela contou que estava cansada desse modo de ver as coisas e propôs: "seja água e ocupe os espaços. Chega de contornar". Da mesma forma com que disse isso olhando nos olhos, encontramos como capa de seu perfil no Facebook a imagem acompanhada da legenda "seja água".

Da mesma forma que Mãe Márcia e Adelaine ocupam seus espaços e realizam seus projetos. Da mesma forma que as imagens das crianças de terreiro ocupam a página no Facebook do livro "Educação nos Terreiros" e o ciberespaço. Da mesma forma, seguiremos em nossas pesquisas: sendo água, ocupando e resistindo.

Narrativas como as aqui discutidas nos impulsionam a continuar a pesquisa e podem ser ouvidas como Àlàáfià, palavra de origem árabe, que significa saúde do corpo, da mente e que tudo está ótimo. Em muitos terreiros de Candomblé, a palavra Àlàáfià pode ser usada como sinal de aprovação, como resposta afirmativa, como o "sim" para tomar determinadas decisões ou realizar certos ritos. Nesta imagem disponível na página do livro "Educação nos Terreiros" no Facebook, Ogan Patryck, do llè Aşé 
Omi Laare lyá Sagbá, em Santa Cruz da Serra, Duque de Caxias, Rio de Janeiro:

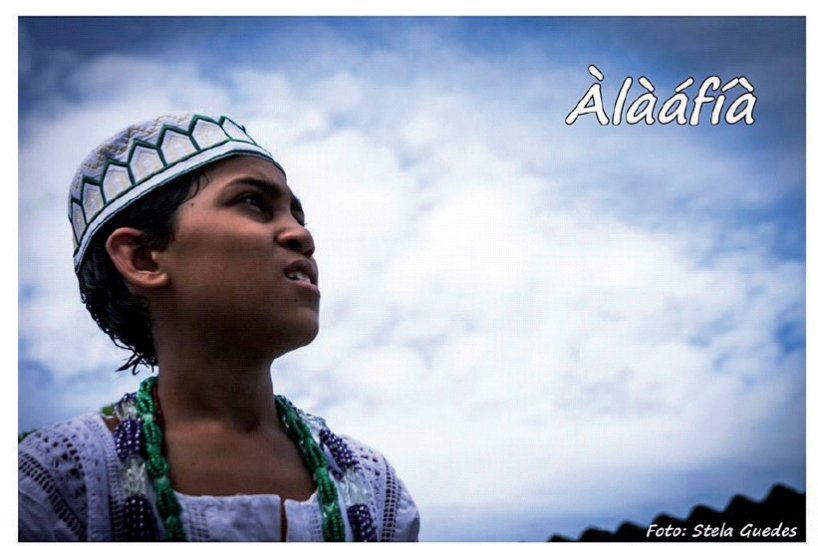

\section{Notas}

* Máira Conceição Alves Pereira é Doutoranda do Programa de Pós-Graduação em Educação - ProPEd/UERJ desde março de 2014. Integra o grupo de pesquisa llè Obá Òyó, sobre redes educativas, racismo e discriminações nas escolas, laicidade e contribuições da cultura afro-descendente e afro-diaspórica para os processos culturais e cotidianos da Educação brasileira, desde março de 2013. Mestre em Administração Pública e Empresarial - EBAPE FGV. Psicóloga - UFRJ. Coordenadora da Escola Brasileira de Economia e Finanças da Fundação Getulio Vargas (FGV/EPGE) desde agosto de 2013. E-mail: mairapereira@uol.com.br

** Stela Guedes Caputo é Doutora em Educação. Professora da Faculdade de Educação e do Programa de Pós-Graduação da UERJ.Formada em Jornalismo (1988), mestrado em Educação pela Pontifícia Universidade Católica do Rio de Janeiro (1998), doutorado em Educação pela Pontifícia Universidade Católica do Rio de Janeiro (2005) e Pós Doutorado em Educação pela UERJ (2009). Professora na graduação e na pós-graduação da Universidade do Estado do Rio de Janeiro (UERJ). Coordenadora o Grupo de Pesquisa lle Oba Oyo. E-mail: stelauerj@gmail.com

\section{Bibliografia}

ALVES, Nilda. Cultura e cotidiano escolar. Revista Brasileira de Educação, número 23, maio/junho/julho/agosto, 2003.

ALVES, N.; GARCIA, R. L. O sentido da escola. Petrópolis: DP Et Alii, 2008.

BRUNO, Fernanda. Máquinas de ver, modos de ser: vigilância, tecnologia e subjetividade. Porto Alegre: Sulina, 2013.

CAPUTO, Stela G. Educação nos terreiros: e como a escola se relaciona com crianças de Candomblé. $1^{\text {a }}$. ed. Rio de Janeiro: Pallas, 2012a.
CAPUTO, Stela G. Artefatos nas redes educativas dos cotidianos de terreiros de candomblé nas relações possíveis com as escolas: discutindo as noções de tradição, cultura e identidade. In: ALVES, N.; LIBÂNEO, José C. (orgs). Temas de pedagogia: diálogos entre didática e currículo. São Paulo: Cortez, 2012b.

CASTELLS, M. A sociedade em rede - a era da informação: economia, sociedade e cultura; v. 1. São Paulo: Paz e Terra. 6a. ed., 1999.

LEMOS, A. Cibercultura: tecnologia e vida social na cultura contemporânea. 5a. ed. Porto Alegre: Sulina, 2010.

LEMOS, A.; LÉVY, Pierre. O futuro da internet: em direção a uma ciberdemocracia planetária. São Paulo: Paulus, 2010.

SANTAELLA, L.; LEMOS, R. Redes sociais digitais: a cognição conectiva do Twitter. São Paulo: Paulus, 2010.

SANTOS, Boaventura de S. Pela mão de Alice: o social e o político na pós-modernidade. São Paulo: Cortez, 1995.

SANTOS, Rosemary S.; SANTOS, Edméa O. Cibercultura: redes educativas e práticas cotidianas. Revista Eletrônica Pesquiseduca, pp. 159-183, v. 04, n. 07, jan-jul 2012.

Data de Recebimento: 25 de setembro de 2014

Data de Aprovação: 25 de outubro de 2014

Data de Publicação: 30 de dezembro de 2014 